\title{
Fracture of a Balloon on a Wire Device During Coronary Angioplasty
}

\author{
Marcel van den Brand, MD, Pim de Feyter, MD, Patrick Serruys, MD, Felix Zijlstra, MD, \\ and E. Bos, MD
}

\begin{abstract}
In a 61-year-old patient with unstable angina an attempt was made to dilate a severe stenosis in a tortuous obtuse marginal branch. The initial attempt with conventional equipment was not successful; although the wire could be advanced distal to the stenosis, a 2.0 balloon did not cross the stenosis. A second attempt with a balloon on a wire device resulted in fracture of this catheter, with the distal $2.8-\mathrm{cm}$-long fragment looped in the left coronary artery. Immediate bypass surgery was performed and the broken fragment was easily removed from the left coronary ostium. The patient made an uneventful recovery.
\end{abstract}

Key words: coronary angioplasty, complications

\section{INTRODUCTION}

Broken angioplasty guidewires have been reported previously [1-7]. Nine patients have been described in whom nine broken fragments could be removed percutaneously $[1,3,5,7]$. Three other cases of percutaneous removal of uncoiled but intact guidewires have been reported $[4,7]$. A Dotter retrieval catheter was used in one case, resulting in incomplete removal after fracture of the wire fragment [1]. A pigtail catheter was employed in two other cases, retrieving the complete fragment, in one of these after femoral arteriotomy $[3,5]$. In another case complete removal was accomplished with a snare-loop technique [7]. In three patients complete removal was accomplished with a bioptome; in one a left Amplatz catheter was successful, and in another case, inflated balloon withdrawal resulted in retrieving the broken fragment [5]. A further three cases have been reported where the lost fragments were surgically removed at the time of operation $[2,4,6]$. To our knowledge no cases have been reported of broken balloon catheters. Recently a new ultra low profile coronary angioplasty device has been introduced. This balloon on a wire system (The Probe TM, USCI, Billerica, MA) has recently been reported as the lowest profile available in balloon catheters, with good preliminary results [8]. We report the first broken balloon on a wire device.

\section{CASE REPORT}

A 61-year-old man was admitted to our hospital for unstable angina. He sustained an inferior myocardial infarction in 1977, but remained complaint-free for the next 10 years. For the year before angioplasty he complained of increasing angina, despite medical treatment, including betablockade, calcium antagonists, and longacting nitrates. Recently he experienced pain at rest and he was admitted to our coronary care unit. The following day angiography showed a well-preserved left ventricular function, with slight hypokinesia of the inferobasal segment. His right coronary artery was occluded proximally, the distal part being filled retrogradely from left anterior descending collaterals. The first obtuse marginal branch showed a 1-cm-long severe obstruction just distal to a bend (Fig. 1A). After discussion with the thoracic surgeons, he was scheduled for angioplasty the next morning. A left Amplatz 2 type guiding catheter (Softip, Schneider-Shiley, Zürich) was introduced during the angioplasty session in the left coronary artery ostium. With some difficulty, a 300-cm-long high-torque 0.014inch floppy guidewire (Advanced Cardiovascular Systems, Mountain View, CA) was positioned across the stenotic part of the first marginal branch (Fig. 1B). An attempt was made to cross the stenosis with a $2.5-\mathrm{mm}$ Piccolino Monorail-Bonzel catheter (Schneider-Shiley, Zürich), but this balloon catheter could not be advanced

From the Divisions of Cardiology and Cardiac Surgery, Thoraxcenter, University Hospital Dijkzigt and Erasmus University, Rotterdam, The Netherlands.

Received July 21, 1988; revision accepted October 20, 1988.

Address reprint requests to Dr. M. van den Brand, Catheterization Laboratory, Thoraxcenter, University Hospital Rotterdam-Dijkzigt, Postbus 1738, 3000 DR Rotterdam, The Netherlands. 
van den Brand et al.
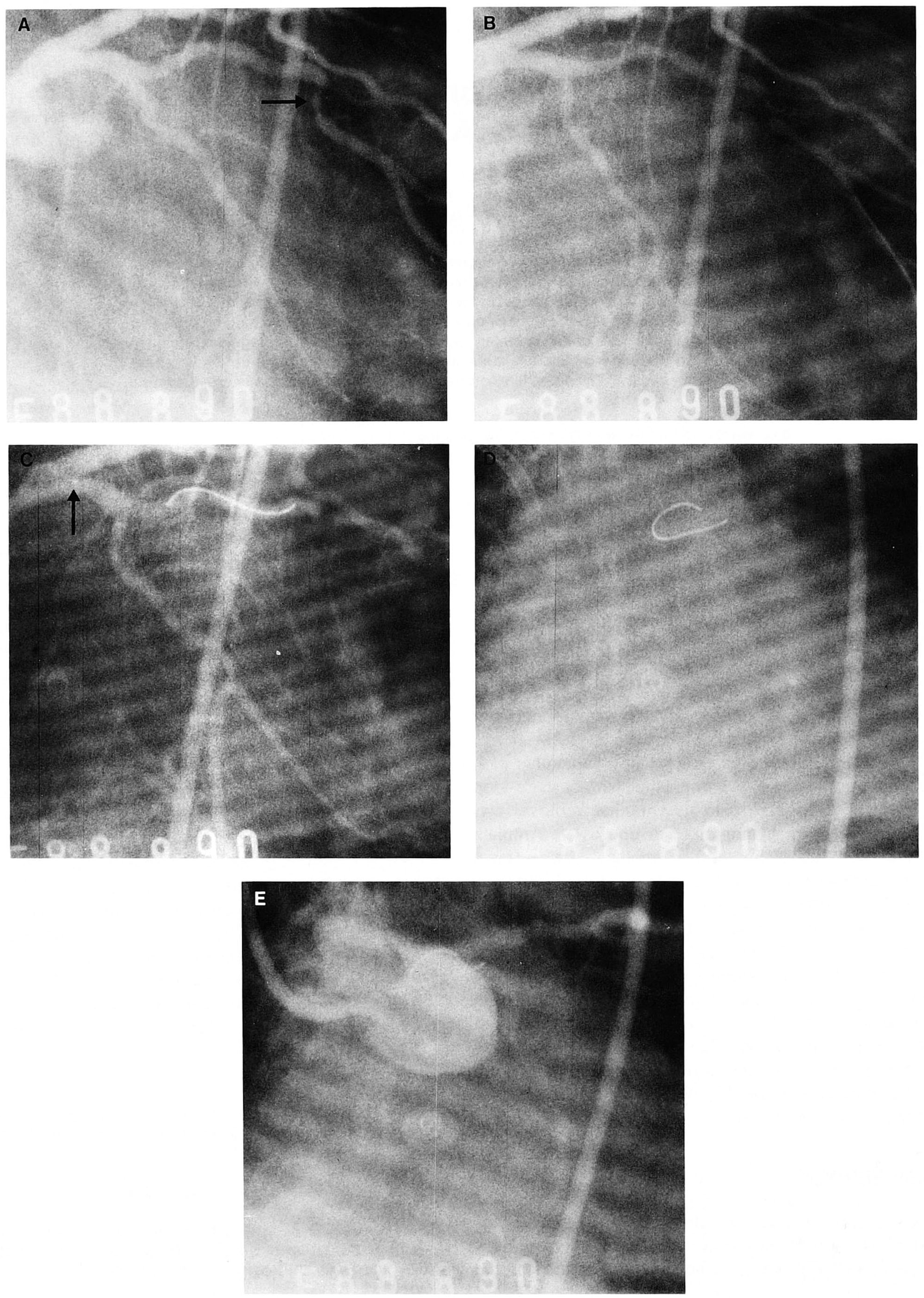


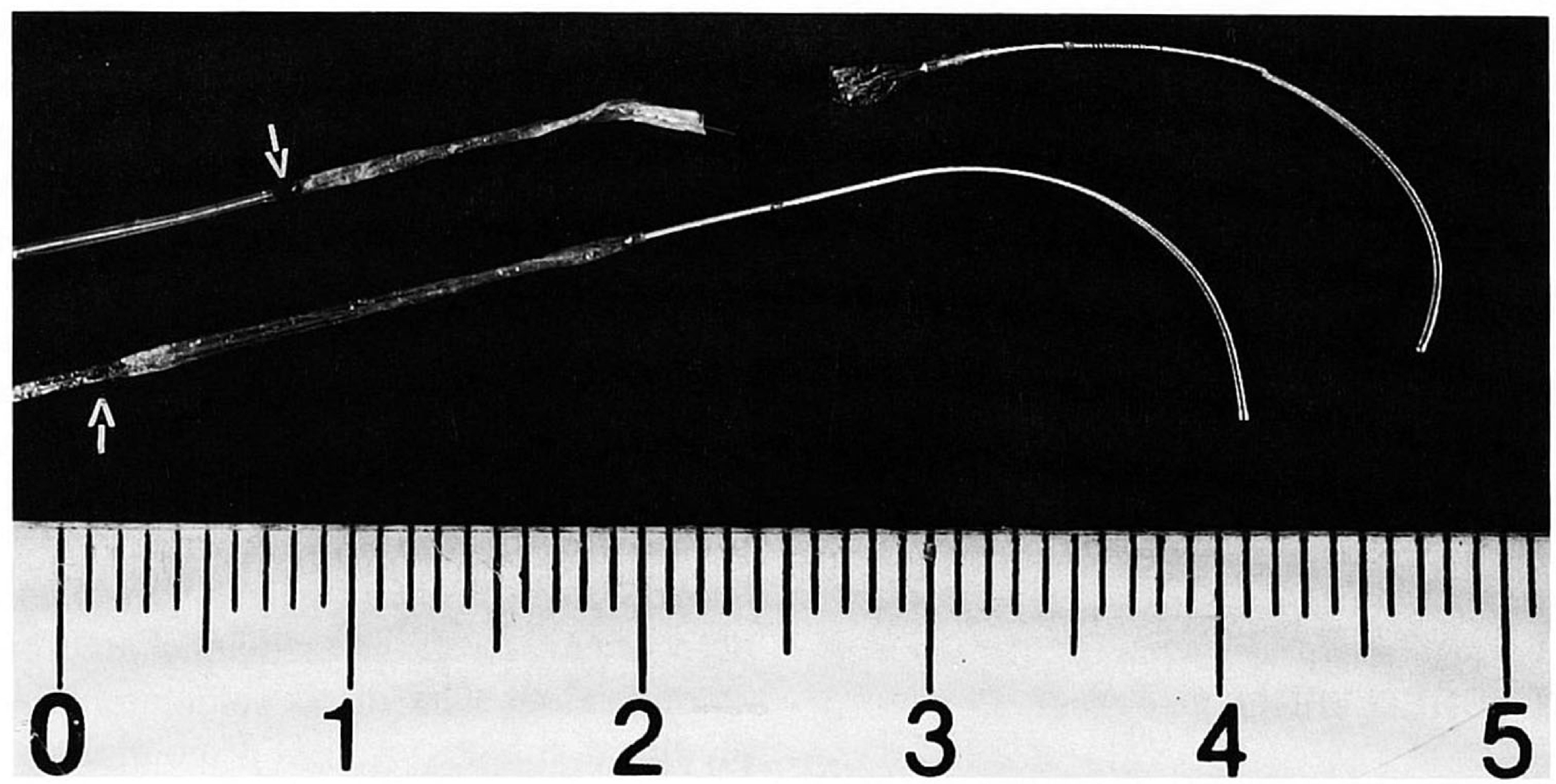

Fig. 2. Fractured balloon catheter (top), compared with intact balloon on a wire device (bottom) also after employment. The breaking point lies within the balloon, with a part of the broken

over the wire through the stenosis. A second attempt using a balloon catheter of the same type but $2.0 \mathrm{~mm}$ in diameter was likewise unsuccessful. It was decided to make an attempt with a 2.0 balloon on a wire system (The Probe TM, USCI, Billerica, MA). During manipulation of this system, the distal obtuse marginal branch occluded (Fig. 1C), and the patient experienced chest pain with ST segment depression in the anterolateral leads and hypotension. The catheter could be withdrawn, but the distal part broke off during this manoeuvre. The tip lay just in the proximal circumflex artery, while the proximal loose end engaged itself in the left main stem artery, leaving a loop of catheter in the ascending aorta (Fig. 1D,E). In view of the difficulties encountered in trying to cross this lesion with a balloon, no attempt was made to retrieve this fragment percutaneously, but a decision was made for emergency bypass surgery. The left internal mammary artery was implanted on the obtuse marginal branch and a saphenous veingraft on the posterior descending artery. The loose distal fragment of the balloon catheter protruded as a loop from the left coronary ostium and could easily be removed after incision of the ascending aorta, just proximal to the takeoff of the left coronary artery. The broken-off tip of the balloon catheter was $2.8 \mathrm{~cm}$ long, with the point of fracture core protruding from the proximal catheter part. The flexible part of the catheter is damaged, but not uncoiled. The radiopaque marker is just proximal to the balloon (arrows). inside the balloon and $1.2-\mathrm{cm}$ balloon length still attached to the proximal wire part (see Fig. 2) (total balloon length $1.5 \mathrm{~cm}$ ). The patient made an uneventful recovery and was discharged 8 days after operation. His maximal serum $\mathrm{CK}$ was 367 I.U. ( $\mathrm{N}<120 \mathrm{IU}), \mathrm{CK}$ MB fraction maximal 17 IU $(\mathrm{N}<10 \%$ of $\mathrm{CK}$ total). The electrocardiogram at discharge showed the same findings as the admission electrocardiogram: old inferior infarct, poor R-wave progression anterior, and a first-degree AV block.

\section{DISCUSSION}

There is little information aside from case reports about this complication of PTCA $[1-4,6]$. Hartzler et al. reported a more complete overview about retained angioplasty equipment components in 5,400 consecutive cases [5]. In their total series of 12 patients with retained fragments, in five this fragment was part of a guidewire and in four the distal tip of a LPS or Microbore balloon catheter. In our own experience of 2,400 consecutive cases, we encountered a broken wire in two patients. One could be removed percutaneously with a loop-snare technique with a Curry catheter as a carrier, removing a
Fig. 1. A: Left coronary artery in right oblique view with caudal angulation. Severe stensosis in first marginal branch at arrow point. B: A 0.014-inch high-torque floppy guidewire has been advanced through the stenotic part of the artery. C: After manipulation of a balloon on a wire device, the distal part of the marginal branch is occluded, the tip of the balloon catheter lies free in the artery, and the balloon marker is in the proximal circumflex artery (arrow). D: Loose fragment of balloon catheter in ascending aorta. E: Contrast injection in the aortic root shows the two ends of the fragment being engaged in the left coronary artery leaving a loop in the ascending aorta. 
broken fragment distally lodged in a small right ventricular branch and the proximal end hanging loose in the ascending aorta, after successful dilatation of a proximal lesion in the right coronary artery. The other broken part of a guidewire was retained in a septal branch of the left anterior descending artery distally, and the proximal part was in the ascending aorta. Because this second complication occurred before dilatation was achieved, this fragment was removed at the time of surgery without complications. These two wires were both manufactured by Schneider and were 0.018-inch steerable types. Both fractures occurred in 1,984 .

\section{TYPE OF FRACTURED WIRE}

The information available in the literature suggests that no conclusions can be drawn regarding specific wires being fracture prone, because no information is available regarding the relative numbers of guidewires used. The reported broken wires were in four instances USCI-manufactured 0.014-inch flexible steerable wires, six broken wires were manufactured by ACS: one was a 0.014-inch high-torque floppy (HTF) type; one was a 0.018-inch HTF type; two were 0.018-inch gold floppy types; one was a PDT wire; and one was a ACS wire of unspecified type. One further report of a broken wire did not mention the manufacturer but was a 0.014-inch flexible steering model. In four other cases involving balloon catheters with restricted guidewire mobility, the tip of this guidewire broke off (three ACS LPS type, one ACS microbore type). To this we can add our own experience with two Schneider 0.018-inch steerable wires.

\section{SITE OF ATTEMPTED LESION IN THE CORONARY ARTERY}

The site of coronary obstruction that led to fracture of the wire while dealing with the stenosis was in four occasions the left anterior descending artery, in another five the left circumflex artery, and in six the right coronary artery. To this we can add our own experience with one left anterior descending, one right coronary artery, and one left circumflex artery. Therefore, no conclusions can be drawn as to whether guidewire fracture is more common in certain vessels, although this complication has not been reported in a bypass graft. Conclusions about the relative incidence of this complication can be drawn only from two previous reports $[4,5]$ and our own experience, which suggests an incidence between $0.1 \%$ and $0.2 \%$.

\section{CAUSE OF FRACTURE}

Regarding the cause of this complication, we must assume that excessive twisting of the wire, especially with the tip lodged in a small side branch or in an atheromatous plaque, may lead to fracture of the wire or balloon. Entrapment of the distal tip of the wire has been reported in four instances $[1,3,5,7]$ or in atheromatous plaque in five cases [5], three plaques totally occluding the vessels. In our experience, two fractures were caused by entrapment of the wire in a side branch, and the broken balloon on a wire device must have been caused by engaging the tip in an atheromatous plaque. In addition one broken wire has been reported after perforation of the vessel wall [2]. We, like ArceGonzalez et al. [4], believe that both manufacturing defects and errors in technique may contribute to this complication. The distal solder joint and tip weld are predilection sites where discontinuation between the inner core and the radiopaque platinum segment may occur. The new balloon on a wire device has a tapered core wire in the distal part. It is remarkable that the distal flexible tip did not break off but that the tapered core fractured within and together with the balloon. Because of inexperience, this device might have been twisted during the procedure more than is advised on the package by the manufacturer. Nevertheless, if the damage occurred while trying to cross the stenosis, it is surprising that the system could be withdrawn with some difficulty to the proximal circumflex artery, where the relation between the radiopaque marker and the distal tip is still undisturbed (Fig. 1C), but broke upon further withdrawal of the catheter (Fig. 1D). It is strange that the point of least resistance should lie within the balloon. Also it is not clear if the ultrathin balloon material consisting of polyethylene teraphtalate, which is only 0.00025 inch thick, is more prone to fracture than the conventional balloon material.

\section{HOW TO HANDLE THIS COMPLICATION}

The first question is whether a loose fragment should be removed. Most authors believe so. We feel that a broken fragment with its proximal end in the ascending aorta or in a proximal part of a coronary artery should be removed. If this complication occurs after a successful dilatation and the proximal part of the broken-off wire is in the ascending aorta, an attempt should be made to retrieve the segment percutaneously by using either a catheter with a loop snare to encircle the fragment $[7,9]$ or employing a Dotter basket catheter [10]. A bioptome has been employed by Hartzler and coworkers [5] in three such cases, all with success. Another possibility employed by Krone [3] and Hartzler et al. [5] is to advance a pigtail ventriculography or left Amplatz coronary catheter to the ascending aorta and, by twisting this catheter, snare the fragment and extract it. If this complication 
occurs before the lesion has been successfully dilated and if part of the wire extends out of the coronary ostium, which procedure should be chosen will depend on the skill of the operator and the likelihood of a successful dilatation being performed after retrieving the fragment. If there have been problems, as in our case, to reach or cross the stenosis, surgery is preferred.

When the fragment is totally retained within the coronary branch, withdrawal has been attempted with an inflated balloon, with recovery of the fragment in one out of two cases [5]. The case with unsuccessful recovery of the fragment with this technique had no clinical event during a 6-month follow-up, although the right coronary artery still contains a 5 -cm-long guidewire tip. Another elderly patient from Hartzler et al.'s series [5] died 2 days after angioplasty as a result of closure of a previously dilated right coronary artery, with a $2-\mathrm{cm}-$ long guidewire tip in his distal circumflex artery. We would have preferred surgery in these two cases if this would have been an acceptable option for both patient and cardiac surgeon. Leaving this fragment behind in the coronary circulation seems justified only if there is small fragment of guidewire retained in a previously occluded vessel [5]. Because this instrument is quite delicate, compared with dilatation catheters, we might finally recommend extraordinary care when using a balloon-ona-wire device (Probe). These recommendations include a stable guiding catheter position, as one cannot manipulate the guiding catheter over the Probe the way one can with a dilatation catheter. The use of an introducer sheath of the Probe into the guiding catheter might be advisable. Extra care with manipulation and torque of this device should be taken when advancing the Probe into distal stenotic lesions, especially in tortuous vessels.

\section{ACKNOWLEDGMENTS}

We gratefully acknowledge the technical assistance of Laetitia Bautz, Claudia Sprenger de Rover, and Jan Tuin in preparing the manuscript and the photographs.

\section{REFERENCES}

1. Steele PM, Holmes DR, Mankin HT, Schaff HV: Intravascular retrieval of broken guidewire from the ascending aorta after percutaneous transluminal coronary angioplasty. Cathet Cardiovasc Diagn 11:623-628, 1985.

2. Khonsari S, Livermore J, Mahrer P, Magnusson P: Fracture and dislodgement of floppy guidewire during percutaneous transluminal coronary angioplasty. Am J Cardiol 58:855-856, 1986.

3. Krone RJ: Successful percutaneous removal of retained broken coronary angioplasty guidewire. Cathet Cardiovasc Diagn 12:409-410, 1986.

4. Arce-Gonzalez JM, Schwartz L, Ganassin L, Henderson M, Aldridge $\mathrm{H}$ : Complications associated with the guidewire in percutaneous transluminal coronary angioplasty. J Am Coll Cardiol 10:218-221, 1987.

5. Hartzler GO, Rutherford BD, McConahay DR: Retained percutaneous transluminal coronary angioplasty equipment components and their management. Am J Cardiol 60:1260-1264, 1987.

6. Bachenheimer LC, Green CE, Rosing DR, Wallace RB: Surgical removal of the intracoronary portion of a fractured angioplasty guidewire. Am J Cardiol 61:946-947, 1988.

7. Watson LE: Snare loop technique for removal of broken steerable PTCA wire. Cathet Cardiovasc Diagn 13:44-47, 1987.

8. Myler RK, Mooney MR, Stertzer SH, Clark DA, Hidalgo BO, Fishman J: The balloon on a wire device: A new ultra low profile coronary angioplasty system/concept. Cathet Cardiovasc Diagn 14:135-140, 1988.

9. Curry JL: Recovery of detached intravascular catheter or guide fragments a proposed method. Am J Roentgenol Radium Ther Nucl Med 105:894-896, 1969.

10. Dotter CT, Rösch J, Bilbao MK: Transluminal extraction of catheter and guide fragments from the heart and great vessels: 29 controlled cases. Am J Roentgenol Radium Ther Nucl Med 111:467-472, 1971 . 